\title{
Created Co-creator, a Theory of Human Becoming in an Era of Science and Technology
}

\author{
AHENKORA SIAW KWAKYE \\ University of Tartu \\ kwakye@ut.ee \\ ORCID: 0000-0002-3583-9012
}

\begin{abstract}
Scientific discoveries and the emergence of cosmological theories such as the Big Bang Theory and evolution have challenged the Christian doctrine of creation and its reliability on many fronts, because the discoveries appear to contradict the Christian account as to how creation unfolded. Lutheran theologian Philip Hefner sees the situation as an additional interpretative task to theologians. He, however, posits that scientific discoveries present opportunities to communicate the Christian message through social and scientific experience in meaningful ways to a broader society. He expresses the notion that religion will remain relevant only if it measures up to science, because we are in a science and technology era. Hefner therefore introduced the concept of created co-creator as a metaphor and analytical tool to explain the meaning and purpose of humans within the biosphere. The concept is characterized by the ability to communicate religion through science and to relate with available models of origin. This work expounds on the concept of created co-creator's ability to explain human technological trajectory in theology. There is also an effort to establish a relationship between Hefner's concept and Haraway's cyborg with an emphasis on the concept's ability to communicate the Christian doctrine of creation through scientific knowledge and why such an enterprise is useful.
\end{abstract}

Keywords: Created Co-creator; Cyborg; Hefner; Evolution; Creation; Religion; Science.

This work was supported by the European Union through the European Regional Development Fund. 


\section{Introduction}

The concept of created co-creator is uniquely characterized by the tenacity to communicate the Christian faith meaningfully to a broader audience by measuring up to scientific experence (Hefner 1993, 9). This article is an effort to illustrate the relevance of this concept to the meaning-making venture of the Christian faith. Philip Hefner introduced the term "created co-creator" in 1984 in relation to the Lutheran doctrine of creation for the late 20th century. He expresses the view that the doctrine of creation is the Christian community's assertion that there is a relationship between God and the world, consequently, the doctrine of creation is a confession of faith. All Christian doctrines should thus correlate consistently with the doctrine of creation to be credible. Additionally, efforts should be made to increase the doctrine of creation's relevance to scientists who may agree on the orderliness of the world but who may reject the Christian talk of plan and purpose and the Marxists who reject all (Hefner 1984, 261-271).

Hefner continued to use and develop his new term in articles over the years and further developed it into a theory in relation to divine purposes for creation in his 1993 book, The Human Factor; Evolution, Culture and Religion. He finds the significance of his term in the dialogue between religion and science, emphasizing the need for metaphysical and religious data for answers to the question of who we are as humans and our purpose. He explains that the Christian faith is a message about the nature of human beings and the destiny of the world. However, the data gathered in such a trajectory becomes empty if they cannot measure up to scientific knowledge and social experience (Hefner 1993, 8). He points to the fact that science is humans' prominent and most successful means of gaining knowledge, and together with technology, a massive stride has been made in knowledge acquisition (Hefner 1993, 9). Conversely, he is also of the conviction that science has something to learn from religion, because even though "the ships that science builds are huge and impressive, the sea is even bigger and rougher" (Hefner 2006, 130).

Hefner made effort to present scientific data in such a way that his concept would simultaneously enlighten scientific understanding and provide a novel interpretation of the doctrine of creation with which many 
religions can identify. God created humans as co-creators and bestowed freedom on them to gain experience and knowledge to be able to do novel things. Nevertheless, humans' activities should have the ability to change the world in ways that appear important and desirable to both humans and the environment (Hefner 2004, 6).

It is on this premise that Hefner builds his theory within the confines of physical and natural science (Hefner 1993, 16). He explains that theology has the task of engaging the possibilities offered by science to articulate the Christian insight in an intelligible and cogent way. In doing so, these insights will appeal to the modern human whose mind has been nurtured in science and lives in a close relationship with technology (Hefner 1993, 17). When it comes to technology, Hefner believes it has become an inseparable part of human's life. It is the source of both human survival and pleasure. Humans are thus tasked with making choices that are theologically coherent and technologically responsible; that nature which is the medium of humans' knowledge is also the medium of humans' technological activities and the source of life (Hefner 1993 [2003]).

In addition to science, the concept of created co-creator harmonizes with religious myths from other cultures such as Hindu dance of Shiva. It has the characteristics of networking for better communication and understanding. Hefner describes his idea of the created co-creator as "a concept or network of concepts that articulate a clear and simple idea that can be elaborated to provide insight into a wide range of data and issues" (Hefner 2004, 2). He also notes that the idea of the created co-creator depends on a great deal of creative imagining; therefore, it fits into the category of "an idea," “a metaphor” or “symbol,” similar to Haraway’s cyborg (Hefner 2004).

Both Haraway's cyborg and created co-creator signify the effort to understand humans and their purpose including their relationship with nature in the field of both theological anthropology and religion and science. Haraway presents her idea of a cyborg to challenge the social-political order and its anthropocentric metrics. Her cyborg which is partly, organism and partly technology breaches the accepted classifications and distinctions between humans and nonhumans and challenges gender and racial disparities. She 
describes her cyborgs as "creatures simultaneously animal and machine, who populate worlds ambiguously natural and crafted" (Haraway 1991, 149).

\section{Created Co-creator, how to Communicate Theology in Science}

As stated in the introduction, Hefner's created co-creator theory is located within religion and science as well as theological anthropology. He builds his theory on the notion that the explosion of knowledge adds to the interpretative task that faces religious faith. Over the years, the relationship between religion and science has been flouted with various challenges. Scholars have continued to find that scientists are generally less religious than others, which has been taken to be a proof that religion and science remain in conflict. But many people see scientists as not only lacking faith, but as actively opposed to religion. This perception sustains a conflict paradigm (Ecklund 2000, 4).

The systematic study of religion and science began in the 1960s as an interdisciplinary study by theologians and scientists. Scholars such as Thomas Forsyth Torrance, professor of Christian Dogmatics, University of Edinburgh (1969) challenged the prevailing view that science and religion were either at war or indifferent to each other by suggesting common grounds for dialogue between the two disciplines. A major pioneer of the enterprise is Ian Barbour, whose books, Issues in Science and Religion (1966) and later When Science Meets Religion: Enemies, Strangers, or Partners?, set out numerous enduring themes for the field, including a comparison of methodology and theory in both fields.

Hefner introduced his idea of created co-creator in the dialogue between religion and science, based on the notion that religion has the responsibility to provide alternative interpretations for the social experience through science. He believes that the faith community's ability to present such interpretations are able to create the avenue to claim that the extension of the Christian concept links the experience and knowledge of God to a wider human experience beyond the community of faith (Hefner 1993, 256). 
Furthermore, the world communities stand to benefit from religious insights if adherents and secularists accommodate each other. Because on one hand, some secularists see religious knowledge as a problem that must be shunted aside to give way to progress, and on the other hand, many religious adherents see science as a deconstructive force that threatens faith. Hefner contributes to the dialogue with the notion that there is a need for both sides to recognise that we live in a three-cornered situation that undergirds and encourages the attempt to relate science and religion for several reasons. First, scientific knowledge has opened up a better understanding of the world, which provides the resource for religion to understand the world. Second, the contemporary socio-cultural situation demands that all knowledge, including scientific and religious should be harnessed to guide humans' action. Third, although science and technology are more clearly a premise of humans' continuous existence than ever before, signs are nonetheless everywhere that people are dissatisfied with the thesis of secularization, which holds that religion and metaphysics are vestiges of our human infancy that will be supplanted by science (Hefner 1993, 10).

Hefner calling for religious data to be interpreted to reflect prevailing knowledge in science is not oblivious of the fact that though scientific theories are supposed to be empirically testable, criteria for scientific theory can be presented in different ways. On one hand, such criteria may be so narrow that most things fall outside of science, while on the other hand, they can be so loose that it becomes difficult to distinguish science from other areas of human culture. Hefner emphasises "fruitfulness" as a theme; he describes "fruitfulness" as discussions that produce truth. He explains that the purpose of his work is not to engage in right and wrong treatise. He nevertheless explains that fruitfulness does not gloat over falsehood but produces truth as its product (Hefner 1993, 26).

\section{Could the Divine play a role in the Evolutionary Processes?}

The concept of created co-created can be used in a totally secular or a religious sense; thus, it fuses the two opposing notions. God is the creator of the 
world, and God created humans to co-create after Himself, which engraves the role of the divine in the concept. But evolution was the means of His creation, thus provides the premise for the evolutionists to consider as well.

The concept stipulates that God's creative insight sparked the Big Bang which marked the beginning of the evolutionary processes - God's own processes. The creation process involved the role of chance, but order and patterns played alongside chance in a complex interrelation similar to the Hindu dance of Shiva (Hefner 1984, 255). In Hindu mythology, time has a cyclic nature: creation repeats itself eternally in a cycle of creation and destruction symbolized by the rhythmic dance of Shiva, the Hindu god. Nature and matter existed in the consciousness of Brahma who is the ultimate reality, the inner essence of all things, infinite and incomprehensible. Nature before creation was inert and could not dance until Shiva willed it. Nature rises from his ecstasy and dances sending pulsing waves through the inert matter of awakening sound. This ignites a dance in matter as well, appearing as a glory round about nature (Marcelo 2005, 11).

The narrative suggests patterning and order in accord with the cyclic rhythm of the dance of nature on Shiva's behest. When nature begins to dance, matter is moved to dance spontaneously due to pulsating waves from nature's rave. This projects the perception that the cyclical dance is ordered and patterned but the action of the waves involves chance. Thus creation emerges as a result of chance and order; Shiva's dance is orderly, but the waves' works involve chance. Creation is attributed to a creator of metaphysical nature. In Shiva's dance, many gods were involved as they gathered in the night of Brahma for the cosmic dance of Shiva, the king of actors. Brahma is the Absolute, the omnipotent to whom creation is attributed, but like many myths, the omnipotent assigns a creating deity (Coomaraswamy 1957).

Here, creation is triggered by the divine; matter sparked by the pulsing waves due to the movements of nature releases the primordial ball that evolves in cycles to generate the celestial bodies and evolve lives. From nature, everything emerged, including Homo sapiens which are constituted by matter. Like Hefner's concept, creation is attributed to a causal deity 
who sustains creation. Moreover, every creature is made up of matter and modelled by cyclic waves, which establishes the kinship among all creatures within the ambience of nature inherent in the created co-creator discourse. Therefore, Hefner's concept inculcates scientific knowledge into theology and possesses the characteristics of harmonizing with other creation stories from other cultures. The concept further provides an adequate reason for humans to act altruistically toward the environment and other creatures due to universal kinship. God initiated the Big Bang explosion from cosmic a singularity over 13 billion years ago, marking the beginning of the evolutionary process (Hefner 2012, 300). These processes resulted in the emergence of the diverse lives within the universe. Thus the divine can have a place in the evolutionary theory as well as the Big Bang.

\section{Createdness and Kinship, Evolution in the context of Created Co-creator}

As stated earlier, the created co-creator philosophy ascribes to evolution as a medium of creation by a divine Creator. Evolutionary science, however, rejects the attribution of origin to a Creator, while creation accounts seem to reject evolution theory. A created co-creator thus signifies the efforts to bring together apparently two opposing views. The concept is a proposal and a hypothesis for a particular kind of understanding of human life and meaning as creatures that emerged from the evolutionary matrix with the purpose of acting in freedom as co-creators in God's evolutionary processes to bring about a wholesome future for the entire creation (Hefner 1993, 27).

Humans' createdness means that they share a certain amount of elements and genes with every other creature in nature, living and non-living, dead and alive, which must inform their actions that harming any member of the commonwealth of nature harms humanity (Hefner 1993, 5). For example, there is a popular African maxim that discourages deforestation, stipulating that "the last human dies with the last tree." The tree representing nature has a direct bearing on the earth's ability to sustain the human species. Destruction of nature is tantamount to the destruction of the human race. 
Furthermore, there is a reinterpretation of the concept of creation; creation means dependence on antecedent factors, such as environment, biology, culture, and its contemporary sources. Humans' created origin is a cursor that they neither design their nature nor their cosmic roles and thus humans cannot be said to be morally superior or inferior to any other species in the same ecosystem. God is the source of their existence as humans to serve the purpose of the created order with their achievements, activities, and possibilities (Hefner 1993, 36).

The concept thus exposes another layer in the scriptural revelation and can reveal something in contemporary technoscientific culture as well. Humans are not so much moving through and over nature, because they are also natural creatures who represent a discrete station on nature's way. They are not sovereign over nature but rather an occasion within nature's sovereignty, because human history including the sacred history, transpired within the matrix of natural history (Hefner 1993, 56). This assertion is in tune with the scientific story that stipulates that, the history of life, like cuneiform on clay tablets, is imprinted on minerals and in genetic code. The minerals are fossils of past organisms, while the code is the DNA information shared by all organisms, a revelation of the family tree of life (Lenski 2012, 9).

Hefner, therefore, gives a theological elucidation to the Darwinian concept by linking the interrelationship and kinship of nature to God as the source. Humans like other creatures are characterized by dependability on God necessitating an altruistic relationship towards all creatures and nature as a whole. To express it in another way, humans are unique among nature nevertheless, humanity shares a common destiny that constitutes the life of the planet (Hefner 1993, 5).

He further demonstrates adherence to evolutionary theory by inferring that human's biogenetically programmed links connect behaviours with other animals, and that "violence towards the other for instance is deeply rooted in our evolutionary past" (Hefner 1993, 161). Linking certain behaviours in human nature to that of animals is akin to Darwinism, which associates mostly negative tendencies in humans, such as violence, biases, and infidelity to animal instincts as a residue of human evolution. It is 
noteworthy that biologists and ethnologists have observed both positive and negative characteristics among human relatives; positive traits such as the ability to learn and teach, altruism and empathy are identified, but the link has focused on the negative over the years. For example, evolutionary psychologists have proposed that infidelity is an evolved adaptation that human beings inherited from their primate ancestors because it is contrary social expectation, and lifelong fidelity within exclusive pair bonds is not evolutionarily adaptive. This is believed to account for the inability of many human males to keep monogamous relationships (Fisher 2011, 112).

Charles Darwin's Origin of Species $(1859,1968)$ posits that there is interrelatedness and kinships among all creations despite virtual diversities. The observable properties of an organism are the result of the interaction between two forces: the process of natural selection, which favours specific genotypes, and the influence of the organism's environment, which modifies the expression of an individual's genes to create certain outwardly visible properties, collectively referred to as the phenotype. "Bodyweight and height of human beings, leaf shape and height growth of trees, and tail length of mice are traits of organisms that result from the interaction of genetic and environmental effects. In the human species, traits like hair, eye, and skin colour hinge more on genetics than the environment and, hence, are hereditary" (Drew 1997, 41).

Hefner similarly expresses such interconnection and kinship of humans and all other creatures scientifically and theologically, because the human person is made up of the basic stuff of the planet. The image of God in the human being indicates that the world itself is capable of that special relationship to which the image of God points (Hefner 1993, 239). Relationality and kinship in evolution are expressed in the created co-creator towards all of creation as a community of God's creatures (Fretheim 2005, 19).

Though there is a kinship between humans and other creatures, humans play a unique role in creation. Therefore theologically they are seen as the imago Dei. The concept expounded from mainly Genesis 1:26-28, describes humanity, both male and female, as being created in God's image and likeness as managers of creation. Darwinists do not recognize the imago Dei concept 
however, there could be some connections. For example, Darwin recognized the ability of humans to exert selection and control evolution. To introduce his idea of natural selection, he referred to how humans had domesticated animals and plants by breeding those with desirable features (Lenski 2012, 10). It should, however, be noted that the suggestion of the human species as specifically and intentionally 'created' by an intelligent and causal God, with the purpose of assigning them as co-creators of the 'created' order, is incompatible to the evolution model as a whole. The Imago Dei status is even more challenging since humans are the greatest contributors to the current negative outlook on climate change, the destruction of natural resources and the threat to varied species of life (Bentley 2017, 1). But Hefner's created co-creator concept suggests that just as human activity is affecting the whole universe negatively, so can humans through consensus building utilize science and technology to provide a more wholesome future for all creatures in the biosphere due to their co-creator (imago Dei) status.

The focus of the co-creator is on the narratives of purpose and creativity found within the natural world in ways that are wholesome to others humans acting with beneficence in creativity. The emphasis on creativity brings the concept close to the metaphor of the cyborg arising out of humans' relationship with technology, which is intricately linked with human createdness. Hefner explains that the technological possibilities as a result of human freedom and creativity point to the moral, theological, and ethical issues involved as created entities that are dependent on antecedent in nature. As imago Dei, humans are capable of exerting tremendous ingenuity and power within the world as God's intentions for humanity and to serve in that agency in altruism (Hefner 1993).

\section{Freedom as an Environment for Creativity that Defines the Homo sapiens}

The need to act altruistically towards other creatures is closely related to both the freedom of humans to act and construct justifying stories as well as human conditioning. Although there is a paradox between freedom and 
conditioning, the human being corresponds to both because Homo sapiens are two-natured creatures that are both conditioned and free. On one hand, as a created being, the human being is conditioned, dependent on antecedent factors, and on the other hand, the human is free to create and even affect the evolution process that created them (Hefner 1993, 30). The co-creators emerged out of the conditioning matrix of genetics and culture that birthed them, and thus the created co-creators are rooted in the bio-historical processes of nature. The progressions bestow divine knowledge and grace, culminating in freedom, for creativity and technology. Humans have the responsibility to engage in technological activities because they are free creatures within nature (Hefner 1993, 45).

Created co-creator represents the human person who is disposed to use the freedom, knowledge, and grace bestowed by God through the evolutionary processes into technologies. Technologies should aim at human flourishing, a wholesome future for nature as a whole and correspond to God's eschatological purposes for creation. Thus, technologies are to enhance the quality of human lives and improve nature rather than harming nature towards the anthropocentric end. This is because nature is a determining factor of human freedom, including creative freedom (Hefner 1993, 46).

The Created co-creator can also represent humans who dwell in the borderlands of contemporary technoculture, as human co-creators that are creative, industrious, compassionate towards nature and humble before God. Technology should not focus on overcoming nature, but rather, harmony with nature for the fulfilment of God's eschatological purpose. Because technological endeavours are attributable to divine knowledge and grace, humans' creative and technological activities are to the glory of God (Hefner 1995, 36).

Human technological activities as created co-creator usher in the concept of the cyborg. Hefner's concept is a theological parallel of Haraway's cyborg, in many respects; they converge and diverge in many areas. They both signify boundary-crossing, because Hefner's theory embodied in the figure of the created co-creator, as the name infers, discusses overtly the question of creativity. The concept however, does not speculate on origins, 
rather creation is synonymous to dependency and co-creator represents co-working with God, just as God continues to work so should humans. We can find duty and purpose from the theological history of Ignatius Theophorus also known as Ignatius Nurono, an early Christian theologian and bishop of Antioch who was calling the image of God Deus Operatius, God the worker to express the relationship, duty and purpose. God is at work in the world, and the point of one's offering is that one labour with Him. The concept is therefore deeply theological based on the notion of God's purpose and intention for creating the human is to work creatively (Yecla 2019, 9).

\section{The Nature of Created Co-creator in relation to the Cyborg}

As stated earlier, Hefner's metaphor has various similarities with Haraway's narratives of a cyborg as a proposal for interpreting human experience and creativity. First, they both represent human engagements with technology and exploration of possibilities with the non-human. Hefner has expressed the relatedness of his created co-creator to Haraway's cyborg by placing the two metaphors in a dialogue (Hefner 2004). He explains that a common meaning central to the ideas of cyborg and created co-creator is the crossing or breaking down of boundaries, both figuratively and literally. He stated that the origin of cyborg could be traced to the dreams of two scientists, Manfred Clynes and Nathan Kline. They conceived an enhanced human, created and fused, a human-machine who is enabled to work in a certain environment hostile to humans. The created co-creator similarly brings the created together with the Creator, the concept of creation together with evolution, while the cyborg brings human and machine together as well as the living and non-living. "Thus the basic idea of the cyborg was to fuse the human and that which is not human, to enable the human to work in an environment that required such a fusion. The boundary between human and technology is transgressed in the very idea" (Hefner 2004, 3).

Second, both are metaphors; the created co-creator is a metaphor representing human creative potentials in line with God's purpose for creation, 
and the cyborg represents a similar endeavour. Anne Kull explains that Haraway uses the cyborg as analytical tool and metaphor for all humans' technological relationships and as a signifier of contemporary postmodern times, marking the changing relationship between humans and technoscience (Kull 2000, 35). There are however conceptual differences between the two metaphors, for example, a created co-creator can find biblical sources among her/his progenitors with link to Eden, but Donna Haraway, however, insists that her cyborg is not from Eden. Nevertheless, both authors use multiple sources thus both created co-creator and cyborg can be called, using Haraway’s words, "polluted categories” (Haraway 2000, 291). On the one hand, sources are linked with World War II and nuclear culture writing, and on the other hand, the source of all pollution including the nuclear pollution whose era ushered in the cyborg. Therefore both co-creator and the cyborg can relate to Eden and urbanization.

Eden represents ambiguity; a paradise, natural, innocence and a loss of innocence including expulsion as well as seclusion. Seclusion is included because one cannot get in or out, and access to Eden rests on God's decision, according to the Judeo-Christian doctrine of creation. The account indicates that the creation of humans occurred in Eden, and this has been used as a basis to contrast and critique urban environments. Technology is perceived as being affiliated with the urban and the artificial in opposition to the natural. The prevalence and potency of technology are perceived as focused on threatening the harmony of the natural environment (Ellul 1964, 79), which might have informed Haraway to excuse the cyborg from Edenic bliss.

Created co-creator, however, reveals that technology is not a stranger in Eden; Eden is ambiguous, and so is our creativity and technology. Within Eden, itself perceived as the citadel of nature marked the beginning of creative work. Indeed, theologically, nature should be acknowledged and appreciated as God's creation and the only medium of understanding the world. Nature is not just the medium of knowledge but also human purpose, which is to co-create (Hefner 1993, 40 - 41). There is an intrinsic relationship between the nature of the created order and the nature of the Creator, which manifests fully in humans. First, createdness connects the human person to God and the 
natural world. Second, the 'created co-creator' opens up new avenues for taking care of nature by first understanding it (Hefner 1993, 4, 41). Theologically, technology began in relationship with both God and nature as discussed below.

\section{Theological Genesis of Technology and the Emergence of the Cyborg}

Genesis 3:7 which is a mythic text rather than historic, recounts the technological endeavour of the first humans; they sewed fig leaves into garments in an effort to cover their nakedness. The effort demonstrates that creativity is inherent in humans at the same time points to the flaws in humans' perceptive abilities that impede the synthesis of more enduring products. In this scenario, the main concern of the couple appears to cover their shame but God provides tunics of skin both for covering and warmth; an enhancement against a new environmental conditions. God action sets off a better synthesis of what is natural and the need for technology and enhancement of the Homo sapiens to facilitate a wholesome existence. We can deduce theologically from the account of Genesis 3:21 that technology started as a joint venture between divinity and humanity within the milieu of nature and with nature.

The created co-creator is, therefore, a metaphor outlining human relationship with technology, inter-human relationships, and the human relationship with nature and God. The concept reveals that creativity is a central theme in theology, the main vocation of the human being. God's purpose was to create a being with the characteristics of the Creator to manage the land, thus joining God and human together. Managing the land is a sophisticated enterprise requiring creativity, knowledge, and grace. The account in Genesis records the technological endeavours of the early humans as well; the family line of Cain was into various technological vocations as recorded in Genesis chapter 4 . The Created co-creator builds a strong bridge between technology and myths by using Christian sources and focusing on creativity. The concept thus brings nature and technology together, that is creatures and their creativity. 
The cyborg equally is not detached from nature, Haraway describes cyborgs as "creatures simultaneously animal and machine, who populate worlds ambiguously natural and crafted" (Haraway 1991, 149). She explains that a cyborg is an image that displaces accepted meanings by forcibly dragging meanings from disparate and incommensurate fields into a union with each other. Thus, the cyborg is part of nature and is a part of technology but there remains fusing, union and hybrid. Similarly, the created co-creator draws meaning from diverse incommensurable fields such as theology, religion, science, technology, anthropology, philosophy, psychology etc., into union with each other, including the effort to unite the Creator and the created.

It may be easy or difficult to discern the cyborg figure, but it challenges who we are, in relation to other beings and phenomena in the world. It is represented in different ways, ranging from speciation, a fusion of human and machine, human and animal or even human and the supernatural. For example, the crone, such as the dolly is a representation of the ultimate blurring of classificatory species boundaries, Robocop, in science fiction, represents a fusion of organism and machine. There are werewolves and vampires which are representations of what is non-human and human, which are both fictional and mythical. Cyborg can mean simple medical devices such as prostheses, and more complicated medical devices such as pacemakers (Kull 2016, 299).

\section{The Role of Myths in Techno-Scientific Society is Vital}

The essence of myths is projected in the created co-creator concept as well. Hefner is of the view that myths and rituals cannot be divorced from humans' existential history thus they are helpful in the ambience of technoculture. They provided the information that supported human life in survival-threatening conditions between 100000 and 20000 years ago (Hefner 1993, 20, 21). Although it is difficult to substantiate the role played by myths and rituals in human survival, the imprints of their use as a major recourse to life-threatening conditions are obvious in nearly every human society. For example, Mihaly Csikszentmihalyi gives an interesting account of the Apulia 
people in southern Italy, in his article, "Mythic Potential of Evolution." He records an experience in a dark cave on the Gargano peninsula, where he touched the depression in a flat boulder believed to have been made by the footprint of the archangel Michael when he came several hundred years ago to rid the countryside of a plague. All around the walls of the deep cavern the local people had hung thousands of silver hearts, legs, and hands to thank Michael for healing them from the results of accidents and diseases (Csikszentmihalyi 2000, 25). There are relics of such mythical narratives in almost every civilization. The salvific intervention of the divine in such stories links with the existential history of the community and their distant relative. This attests to the validity of Hefner's claim.

There is also the account of the Australian aborigines who depended on the rains of the yearly monsoon to replenish their wells for subsistence. According to their tradition, the sudden appearance of clouds, lightning, and rain means the creator serpent Yurlungur, who created the first man and woman, came back each year to copulate with the sky in order to generate the rainfall needed for the survival of his progeny (Csikszentmihalyi 2000, 25). Here humans were created and not evolved, but like the other creation narratives, the mode of creation is scant. Though the narrative differs from the Bible account, both accounts share similarities such as an origin by a causal creator and dependency on such a creator. The creation from one source also represents universal kinship. These shared grounds inherent in the concept of created co-creator and the myth provides an easy avenue for the Australian aborigines to identify with created co-creator concept. The created co-creator concept thus possesses the potential to reconcile the myths of various peoples and contemporary scientific knowledge.

A similar narrative is the myth of the Hopi Indians of the United States, which attributes creation to a deity referred to as Taiowa who is believed to be the absolute; omnipresent, omniscient, and omnipotent. Everything else was endless space, no beginning and no end, no time, no shape, and no life. However, the immeasurable void had its beginning and end, time, shape, and life in the mind of Taiowa. He created Sotuknang and sent him to create the universe in proper order so they may work harmoniously with 
one another according to his plan. Sotuknang gathered from endless space that which was to be manifest as solid substance and moulded it into forms (Marcelo 2005, 9, 10). Here, as in many myths, the Infinite creates the finite, giving concrete shape to matter and moulding it into forms that are in tune with the concept of created co-creator.

Myths and rituals have contributed immensely to the survival of the human species. Unfortunately, they cannot fit into a test tube, and they are neither universal nor testable but they are imminent in human evolutionary history. The relevance or strength of a myth does not lie in its being right or wrong but rather the ability to explain and make sense of particular situations. Myths cannot be interpreted scientifically; rather, they are properly understood within the context of the culture from which they emerged (Marcelo 2005, 8). The above myths point to a creator deity, the Big Bang, which started the evolutionary process, is thus attributable to either Yurlungur or Taiowo or Shiva depending on the culture involved. Since there are science and religious dialogue in almost all religions, it is possible to interpret scientific models and theories in various cultural-religious contexts and that regardless of religion or culture, it is advisable to use the best of contemporary scientific knowledge. I am of the conviction that all religious traditions can be re-interpreted taking into account prevailing social experience. The deities of the world could, therefore, own the evolutionary process as a means of bringing forth a cosmos, where human beings are active, talented, creative co-workers along with the rest of nature, which characterizes the created co-creator theory.

\section{Co-creator and Optimistic view of Technology}

Some theologians see the preface "co" associated with the term created co-creator as reflecting an optimistic view of technology or elevating the human status to that of God's. One of such scholar is Vitor Westhelle (2004, 748 ), who sees an aura of optimism surrounding Hefner's concept. He links the "co-creator" to the exclusive Hebrew word bara, translated into the Septuagint as poiesis, which refers to the ability to create something from 
nothing. He is of the view that poiesis is used solely in reference to divine activity, therefore, the concept is scandalous because it elevates the human creature to the level of the Creator by placing the human creative activity alongside that of God.

But first and foremost, Hefner does not derive his concept from Old Testament theology. He does not attempt to equate his term with any text in the Old Testament. Assuming the term could be linked to Old Testament texts, it would be far from bara and its corresponding Greek poiesis. In my opinion, created co-creator rather corresponds closely to two Hebrew words avodah and mlakhah which were first used in Genesis 2:15 to mean creativity and laborious activities. Avodah is translated into English as 'to work, ' to serve,' 'to till, while mlakhah indicates 'to hedge about,' 'to guard,' 'to protect,' 'to attend' (bible-discovery.com 2019). Both words stipulate the utilization of available resources through the application of skills and strength. When used together, they spark the concept of creativity, including the creative power from learning to control. Hefner places the human ability to create on grace and knowledge which are both derivatives from God. Furthermore, the imago Dei status in the co-creator is bestowed by God for His purpose and will.

On the aspect of an optimistic view of technology, it is associated with transhumanism rather than theological anthropology. Transhumanism is the quest for longevity, artificial intelligence, hybridity, and virtual reality based on the premise that the human species, in its current state represents a work in progress, and through the synergy of technologies, humans can move into the next stage of evolution to be able to overcome all biological limitations (Bostrom 2005). Transhumanism unlike the created co-creator concept rejects the theological anthropology that God is the source of the created order and the evolutionary process, and humans are intrinsically linked with nature. Transhumanism rather, relies on a dynamic, materialistic, and evolutionary power-ontology, which conceptually favours the transgression of biologically and culturally imposed limitations (Lipowicz 2019, 2008). Created co-creator sees culture as a medium of improvement and refinement of human nature, locating the human species as kin intricately woven with other creatures. 
Transhumanists, however, focus on techniques of human enhancement in the areas of genetic engineering, information technologies, the development of molecular nanotechnology, and artificial intelligence (Bostrom 2003, 493). Thus, the created co-creator travels in different wavelengths with the technological eschatologists who desire to transcend over the material world because their salvation is found in human ability.

\section{Conclusion}

Hefner's created co-creator theory defines creation as dependence; humans depend on nature, and the entire nature depends on God. The concept effectively explains how the religious concepts of creation can be explained through prevailing concepts such as the evolutionary theory to enhance understanding. The concept also reveals the roles that religion could play for better understanding of non-religious theories, such as attribution of the evolution to God. The concept exposes the vast avenue and possibilities of making faith meaningful through contemporary social experience to be relevant in our secularized techno-scientific society. Furthermore, the concept reveals the possibility for the faith community to be motivated to accept technology as humans' vocation, ordained by God. And thus technology should be designed to protect nature from pollution in view of humans' kinship with nature. The kinship expounded within the concept is hence a call to use science and technology to mitigate the current environmental crises and forestall future ones.

A conspicuous theme within the concept is humans' freedom which exists simultaneously with human conditioning. The purpose of freedom is to create, because humans are able to create if society is free from problems such as, extreme hunger, thirst, diseases and oppressions etc. Furthermore, humans' creative works should enhance nature because humans are also from nature and is a determinative factor of human freedom as well as existence. This exposes the reality of human conditioning and dependency. The fact that humans are created rational and free comes with the responsibility to seek for the rights and wellbeing of other species. 
Hefner's concept is similar to Haraway's cyborg; they are both metaphors representing boundary-crossing and endless possibilities of human creativity, but the two authors employed different sources. Created co-creator does not represent an optimistic view of technology but rather liberation through creativity in recognition of the universal kinship of all creatures to the glory of God. The concept is therefore useful in the meaning-making effort of religion in general and Cristian faith in particular. Hefner's created co-creator provides a useful way for inter-religious dialogue and provides avenues for religion to relate with science to enhance the relevance of faith in our contemporary technoculture.

\section{Bibliography}

Ayala, Francisco J. 2008. From Paley to Darwin: Design to Natural Selection. In Back toDarwin: A Richer Account of Evolution, edited by John B. Cobb Jr., 50-70. Grand Rapids, Michigan, Cambridge: William B. Eerdmans.

Barbour, Ian. 1966. Issues in Science and Religion. New York: Vantage.

Bentley, Wessel. 2017. "Are we special? A critique of imago Dei." HTS Teologiese Studies/ Theological Studies 73: 2072-8050.

Bostrom, Nick. 2003. "Human Genetic Enhancements: A Transhumanist Perspective.” The Journal of Value Inquiry 37: 493-506.

Bostrom, Nick. 2005. "Review of Contemporary Philosophy." Transhumanist Values 4: 87-101.

Coomaraswamy, Ananda K. 1957. "The Dance of Shiva," In the Dance of Shiva: Fourteen Indian Essay. New York: The Noonday Press.

Csikszentmihalyi, Mihaly. 2000. “The Mythic Potential of Evolution.” Zygon: Journal of Religion and Science, 35: 25-38.

Ecklund, Elaine Howard. 2019. Science vs. Religion; What Scientists Really Think. USA: Oxford University Press Inc.

Ellul, Jacques. 1964, 1954. The Technological Society. Translated by John Wilkinson. New York: Vintage Books.

Fisher, Helen E. 2011. "Serial monogamy and clandestine adultery: evolution and consequences of the dual human reproductive strategy," In Applied Evolutionary Psychology, edited by S. Craig Roberts. 93-112. Oxford: Oxford University Press,.

Gleiser, Marcelo. 2005. The Dancing Universe: From Creation Myths to the Big Bang. Dartmouth: College Press. 
Haraway, Donna. 2000. “A Cyborg Manifesto: Science, Technology and Socialist-Feminism in the Late Twentieth Century". In The Cybercultures Reader, edited by David Bell and Barbara M. Kennedy, 291-324. London, New York: Routledge.

Hefner, Philip. 1984. “The Doctrine of Creation.” In Christian Dogmatics; The Creation, edited by Carl E. Braaten and Robert W. Jenson, 269-362. Philadelphia: Fortress Press.

Hefner, Philip. 1993. The Human Factor: Evolution, Culture and Religion. Minneapolis: Fortress Press.

Hefner, Philip. 2004. The Created Co-Creator Meets Cyborg, accessed February 6, 2020, http://www.metanexus.net/essay/created-co-creator-meets-cyborg.

Hefner, Philip. 2006. Spiritual Transformation and Healing: Anthropological, Theological, Neuroscientific, and Clinical Perspectives, edited by Joan Koss-Chioino and Philip Hefner. Oxford, UK: Altamira Press.

Kull, Anne. 2000. A Theology of Technonature Based on Donna Haraway and Paul Tillich. PhD diss., Chicago: University of Chicago.

Kull, Anne. 2016. “Cyborg and Religious? Technonature and Technoculture.” Scientia et Fides 4: 295-311.

Lenski, Richard E. 2012. "Evolution in Action A 50,000-Generation Salute to Charles Darwin.” In Microbes and Evolution: The World That Darwin Never Saw, edited by Stanley R. Maloy \& Roberto Kolter, 9-16. Washington, DC: ASM Press.

Lipowicz, Markus. 2009. “Overcoming Transhumanism: Education or Enhancement towards the Overhuman?” Journal of Philosophy of Education 53: 200-214.

Torrance, Thomas F. 1969. Theological Science. London: Oxford University Press.

Westhelle, Vítor. 2004. “The Poet, The Practitioner, and the beholder: Remarks on Philip Hefner's Created Co-Creator.” Zygon 39: 747-754.

Yecla, Gem. 2019. “Co-Creation Spirituality Participating in God's Ongoing Work of Creation through Spiritual Direction and the Spiritual Exercises.” The Way 58: 7-18. 